\title{
Arthritis liaison: a First Nations community-based patient care facilitator
}

\author{
Valerie Umaefulam, PhD (1); Adalberto Loyola-Sanchez, MD (1); Valene Bear Chief, LPN (2); Ana Rame, PhD (1); \\ Louise Crane, BA (3); Tessa Kleissen, BN (1); Lynden Crowshoe, MD (1); Tyler White (2); Diane Lacaille, MD (4,5); \\ Cheryl Barnabe, MD $(1,5)$
}

Tweet this article

\begin{abstract}
Introduction: Arthritis is a leading cause of disability in First Nations communities and is often accompanied by other chronic diseases. Existing care models prioritize accessibility to specialty care for treatment, whereas patient-centred approaches support broader health goals.

Methods: A patient care facilitator model of care, termed "arthritis liaison,” was developed with the community to support culturally relevant patient-centred care plans. Following a one-year-long intervention, we report on the feasibility and acceptability of this care model from the perspectives of patients and health care providers.
\end{abstract}

Results: The arthritis liaison served as a bridge between the clinicians and patients, and fostered continuity, helping patients receive coordinated care within the community.

Keywords: arthritis, chronic disease, patient navigation, First Nations, Indigenous Health Services, health care outcome and process assessment, qualitative study

\section{Introduction}

First Nations populations have increased prevalence $^{1,2}$, severity ${ }^{3,4}$ and undertreatment of arthritis ${ }^{5}$. Inequities in determinants of health related to the legacy of colonization $^{6}$ affect health status ${ }^{7}$. Health care providers either consciously (through disregard for cultural values) or unconsciously (by failing to provide culturally relevant care) disempower patients ${ }^{8}$. This can affect the continuity of care and undermine efforts to support effective disease management and wellbeing ${ }^{9}$.

Novel ways of delivering relevant care that addresses social, geographical and economic barriers are needed to improve outcomes among First Nations people with $\operatorname{arthritis}^{10}$. In keeping with principles of community empowerment and self-determination, we should prioritize Indigenousled initiatives ${ }^{11}$ and those that support Indigenous providers in the workforce ${ }^{12}$.

Case management models of care, and the closely related patient navigation care models, are effective approaches in chronic disease management ${ }^{13-16}$, but the benefits of the models in terms of arthritis management vary ${ }^{17-19}$. In addition, the models have neither been implemented nor evaluated in the context of care of Indigenous patients with arthritis. While these models aim to counter the focus of specialist care on single disease entities and could support the use of cultural practices, we propose that they may be a way to deliver arthritis care in Indigenous communities.

\section{Highlights}

- Care models that address health in a culturally relevant manner and also address the many barriers to care may resolve care gaps more effectively and optimize health outcomes of First Nations people with arthritis and comorbidities.

- The arthritis liaison model of care was built on case management functions informed by Indigenous community members to ensure care facilitation was included in the model.

- The scope ranged from medical aspects to personal support, and was consistent with a culturally appropriate patient-centred approach dictated by patients' needs.

In this report, we describe the development, implementation and accessibility evaluation of an arthritis liaison model of care in a First Nations community.

\section{Methods}

\section{Setting}

Siksika Health Services is a self-determined comprehensive primary health care organization. A rheumatology outreach clinic has been offered since 2010. The goal of the clinic is to facilitate access to specialist assessment and treatment in the primary care setting ${ }^{20}$. The research team compared 
the quality of treatment provided by this clinic to nationally endorsed performance indicators $^{21}$. We also sought service-user perspectives on the gaps remaining in arthritis care $^{22}$. These perspectives supported the need to further enhance the care model, by providing services that improve physical and mental functions, by improving communication, continuity of care and community education and by increasing peer connections and support ${ }^{22}$.

\section{Intervention co-development with community}

The research team proposed an intervention built on a case management model that focused on needs assessment and the development of treatment and care plans, linking clients to services, monitoring and advocacy $^{23}$. We established a research advisory group that included community members and Elders with arthritis conditions, representatives from Siksika Health Services and the former Indigenous patient representative of the Canadian Arthritis Patient Alliance. The principal investigator of the research team is Métis.

In place of "case manager," the community chose the term "arthritis liaison." The research advisory group informed duties of the arthritis liaison, patient recruitment strategies and evaluation components of the research. We hired and trained a community member with nursing experience as the arthritis liaison to support arthritis care needs and self-management skills. In addition, the arthritis liaison attended a one-week course in motivational interviewing and action plan facilitation.

\section{Implementation}

The arthritis liaison provided medical and personal support for one year. Support included regular communication with participants and their health care team (in person, by telephone or via text messaging). Support for the monthly arthritis specialty clinic was also provided, namely administering prescribed injections and facilitating group-based activities for patients and their families.

\section{Participants}

We recruited Siksika Nation patients with inflammatory arthritis or osteoarthritis attending the rheumatology outreach clinic at Siksika Health and Wellness Centre to the intervention. Patients had to be
19 years or older, and in addition to their arthritis condition(s), had to have at least one of the following: diabetes, obesity, hypertension, cardiovascular disease or chronic obstructive pulmonary disease.

\section{Accessibility evaluation and analysis}

We documented the number of interactions between the arthritis liaison and participants as well as the reasons for these interactions. We used qualitative methods to explore, from the perspective of each participant and the health care providers in the community, how the arthritis liaison facilitated care. We recorded the semistructured interviews, and two researchers transcribed and coded them independently using Dedoose software (SocioCultural Research Consultants, LLC, Los Angeles, CA). We compared codes for consistency and interrater reliability. Thematic analysis was conducted and interpreted in relation to principles of patient-centred care and concepts of "culturally safe care for Indigenous peoples in Canada" ${ }^{24}$. As the arthritis liaison identified as female, interview quotes refer to "she."

\section{Ethics}

This study was approved by Siksika Health Services leadership and by the University of Calgary Conjoint Health Research Ethics Board (REB 15-1961). Roles and responsibilities of the research team to the community were documented in a memorandum of understanding. All participants provided written consent. The research was performed in accordance with ownership, control, access, and possession, or $\mathrm{OCAP}^{25}$ principles of First Nations research, and the 1964 Declaration of Helsinki and its later amendments.

\section{Results}

\section{Participants}

Between May 2017 and December 2018, 23 patients enrolled in the study. Participants were predominantly female $(80 \%)$ with a mean age (standard deviation) of 59 (12) years. Rheumatoid arthritis $(\mathrm{n}=13)$ and psoriatic arthritis $(n=5)$ were the most frequent types of arthritis, and diabetes ( $\mathrm{n}=9$ ) and hypertension $(\mathrm{n}=6)$ were the most frequent comorbidities. Seventeen participants completed the full intervention period ( 2 withdrew, 1 died and 3 were lost to follow-up).

\section{Accessibility}

The frequency and types of interactions between the arthritis liaison, participants and the health care team are shown in Table 1 .

The narratives of the participants ( $n=14$ ), health providers $(n=10)$ and the arthritis liaison showed that the model of care improved accessibility and was accepted and considered to be culturally appropriate.

Participants valued the flexibility in communications and interactions with the arthritis liaison, who adapted to their needs and circumstances. Examples of adaptation included meeting locations for injections and check-ins (e.g. home visits, for coffee); the communication methods used (e.g. text, phone); the extent and frequency of communications; and communication styles (e.g. formal and informal).

Trust in the arthritis liaison, created through respectful, supportive, compassionate and accountable interactions, made it easier for the participants to engage in their treatment. The arthritis liaison engaged

TABLE 1

\section{Snapshots of the arthritis liaison's interactions in facilitating care}

\begin{tabular}{|c|c|}
\hline Type of interaction & Mean (SD) number \\
\hline Face to face & 8 (5) hours per participant \\
\hline Text messages & 70 (58) messages to each participant (range: 9-194) \\
\hline Home visits & 112 \\
\hline Health assessments & 74 \\
\hline Brief action plans & $2-5$ goals per participant \\
\hline $\begin{array}{l}\text { The arthritis liaison accompanied the patient to } \\
\text { their appointment or communicated with the } \\
\text { health care provider to advocate on their behalf }\end{array}$ & $\begin{array}{l}168 \text { appointments total (range: } 1-7 \text { per participant; } \\
\text { primary care, } 8 \text {; allied health, } 27 \text {; home care, 23; } \\
\text { medical transportation, 18; investigations, } 2 \text {; } \\
\text { specialist, } 90 \text { ) }\end{array}$ \\
\hline
\end{tabular}


with a variety of health care providers in the patient's circle of care to advocate for the patient's interests or for additional resources, including organizing allied health consultations and transportation to appointments, helping access medication and being present during medical appointments.

Finally, through action planning, reminders and facilitation, the arthritis liaison supported engagement in care plans such as accessing resources or achieving set goals.

Following are themes about the accessibility of the arthritis liaison model of care and patient-participants' and providers' quotations to illustrate these themes.

\section{Engaging with patients according to individual needs and preferences}

...she's checking up on us, making sure, you know, if we need anything or if anything's come up, you know, she's just a phone call away too. - Participant 23

She is so easy going, I'm glad that she was open and flexible to my time, 'cause we'll have an appointment to see each other at 2:00, but I'll be doing a workshop somewhere else, and she'll be so understanding. - Participant 01

She answers immediately-if not immediately, like within 1 hour and better, by texting. - Participant 18

She has been a pretty critical point of contact for patients. From what I am hearing from people is they know how to contact her, and they can kind of get answers and stuff expedited. - Provider 04

\section{An accountable relationship created trust, providing the opportunity to access health information}

She's very, like when she says she's gonna do something, she does.[...] If she says, "I'll be there", she's gonna be here. - Participant 17

Even when she wasn't sure of something that I had asked her, she said you know what, I'm gonna find out, I'm gonna ask [name], I'll research it, and I’ll get back to you. - Participant 01
Yeah, and I feel comfortable talking to her about my pain and what's hindering me today or whatever. You know, I feel comfortable with that, yeah. I feel, it's all about trust for me, and if I don't trust someone and I feel like they're not really trying to help me, you know, I could, I stand back a little. But when I know someone's helping me in, that's where I can trust them. - Participant 06

If I had any questions about ... Like ... she'd explain when I first started that metho [methotrexate], like if there was something I'd need, she'd explain, like what the medication was for... And she just...would suggest stuff. Like, you know, maybe just sit for a while, before you even try to get up. Like just helpful hints. - Participant 23

I think a lot of them kind of began to understand what they were going through. They noticed when they'd have, like lower numbers on the EQ5 [D; a measure of quality of life]. They could tell when they were in a flare, and they liked to look back at the trends. - Arthritis liaison

\section{Facilitation of communication with health care providers}

If the doctor needs information and I can't explain the words properly [the arthritis liaison] can do it for me... - Participant 06

Like the last time I seen Dr. [name], there were some of the things that I forgot that I was gonna ask her and then [the arthritis liaison] was in there, and she just says, "Oh yeah, you were gonna ask her about this." Like I said, she's my memory, right? - Participant 13

I do believe that it's opened the communication lines, so...people are advocating for themselves more... and are more willing to share, uhm, what goes on in between visits. - Provider 01

Encouraged utilization of available resources and enabled activation of treatment plans

There was a portion of them who would go on about needing these resources, but when it came down to it and the resources were right there in front of them, they didn't utilize it... But I think part of it is trust... - Arthritis liaison

I think that that's been a beneficial effect... Again it increases the efficiency of what I need to do because I don't have to wait for a lab value to come back... or have to fill out the requisition again. Like, it's already done. - Provider 02

\section{Threats to feasibility}

Although the intervention was generally well-received, we faced some challenges in continually engaging participants in this model of care. Problems arose due to time conflicts, limitations in telecommunications (inaccurate or outdated phone numbers) and personal, family and/or community crises.

The arthritis liaison's availability was limited to working hours, which proved to be a logistical concern as this did not always align with participants' preferred time for interaction. Transportation barriers were also a limitation when the arthritis liaison could not go to patients' homes or patients could not come to the clinic.

We approached the project longitudinally, seeking permanent funding within the operational budget and with a consistent community-based staff member employed in the role so that we could support them and allow them to thrive in their specialized role. Unfortunately, competing priorities for funding arose in the community, and it was not possible to sustain the role after the study funding ended.

\section{Discussion}

The arthritis liaison model of care, codeveloped with an Indigenous community, assisted Indigenous arthritis patients in navigating the health service to take care of their needs and focus on their personal patient-centred care plans. Both the patients who participated in our study and the community health care providers valued this model of care. One participant's narrative illustrates the overall perception of the arthritis liaison model, noting that they were "not a miracle worker to make my arthritis go away, [but] she's there to help you with the medical part and the moral support."

Health system navigation is complex in chronic disease management. Here, the 
arthritis liaison served as a bridge between the health care providers and patients, and fostered continuity. A metasummary of qualitative studies of patient experience of care continuity concluded that a single trusted clinician that partners for decision making and system navigation is at the core of what people perceive as adequate continuity of care $^{26}$. Patient support, education, case management and system navigation delivered by trained personnel who are trusted community-based members are effective approaches in chronic disease management, especially in underserved, vulnerable communities ${ }^{27}$. In this study, our model of care appears to have enabled patients to receive coordinated, continuous care within the community by virtue of the work of the arthritis liaison.

In this real-world study, not all patients wished to complete evaluations, and we are only able to report the perspectives and outcomes of patients fully engaged in the model of care.

Our findings are likely relevant to many diverse Indigenous peoples and communities in Canada.

\section{Acknowledgements}

We are grateful to Cheryl Sorenson and Margaret Kargard, from Siksika Health Services. They were instrumental in the implementation of the model of care.

We would also like to thank Arthritis Community Advisory Council Members, including Sharon Calf Robe, Tangee Scalplock, Lesley Stimson and Rosalyn Manyguns.

\section{Funding}

This study was funded by The Arthritis Society (SOG-14-130), the Canadian Initiative for Outcomes in Rheumatology Care and the Canadian Institutes for Health Research (Team Grants in the Inflammation Signature Initiative: PRECISION (Preventing Complications from Inflammatory Skin, Joint and Bowel Conditions, THC-135235, CIHR-IRSC: 0492004733, FRN\# 135235)).

VU is funded by a University of Calgary Eyes High Postdoctoral Scholarship. ALS was funded by a CIHR Banting Postdoctoral Fellowship.

\section{Conflict of interest}

The authors declare that they have no conflict of interest.

\section{Authors' contributions and statement}

VU: Analysis, writing original draft and review and editing

ALS: Conceptualization, analysis, funding acquisition, investigation, methodology, project administration, supervision, writing original draft and review and editing

VBC: Investigation, resources, writing review and editing

AR: Analysis, writing original draft and review and editing

LoC: Conceptualization, funding acquisition, supervision, writing review and editing

TK: Data curation, investigation, project administration, supervision, analysis, visualization, writing review and editing

LyC: Conceptualization, funding acquisition, methodology, supervision, writing review and editing

TW: Conceptualization, funding acquisition, project administration, resources, writing review and editing

DL: Conceptualization, funding acquisition, investigation, methodology, project administration, supervision, writing review and editing

CB: Conceptualization, analysis, funding acquisition, investigation, methodology, project administration, resources, supervision, visualization, writing original draft and review and editing

The content and views expressed in this article are those of the authors and do not necessarily reflect those of the Government of Canada.

\section{References}

1. Barnabe C, Hemmelgarn B, Jones CA, et al. Imbalance of prevalence and specialty care for osteoarthritis for first nations people in Alberta, Canada. J Rheumatol. 2015;42(2):323-8. https:// doi.org/10.3899/jrheum.140551

2. Barnabe C, Jones CA, Bernatsky S, et al. Inflammatory arthritis prevalence and health services use in the First Nations and non-First Nations populations of Alberta, Canada. Arthritis Care Res (Hoboken). 2017;69(4):46774. https://doi.org/10.1002/acr.22959
3. Nagaraj S, Barnabe C, Schieir O, et al. Early rheumatoid arthritis presentation, treatment, and outcomes in Aboriginal patients in Canada: A Canadian Early Arthritis Cohort study analysis. Arthritis Care Res (Hoboken). 2018;70(8):124550. https://doi.org/10.1002/acr.23470

4. Hurd K, Barnabe C. Systematic review of rheumatic disease phenotypes and outcomes in the Indigenous populations of Canada, the USA, Australia and New Zealand. Rheumatol Int. 2017;37(4):503-21. https://doi.org/10 .1007/s00296-016-3623-z

5. First Nations Information Governance Centre. National Report of the First Nations Regional Health Survey: Phase 3: Volume One. Ottawa (ON): FNIGC; 2018 Jul.

6. Reading CL, Wien F. Health inequalities and social determinants of Aboriginal peoples' health. Prince George (BC): National Collaborating Centre for Aboriginal Health; 2009.

7. Public Health Agency of Canada. Health Status of Canadians 2016: Report of the Chief Public Health Officer. Ottawa (ON): PHAC; 2016.

8. Allan B, Smylie J. First Peoples, second class treatment: the role of racism in the health and well-being of Indigenous peoples in Canada. Toronto (ON): Wellesley Institute; 2015.

9. World Health Organization. Basic documents: forty-ninth edition (including amendments adopted up to 31 May 2019). Geneva (CH): World Health Organization; 2020.

10. Thurston WE, Coupal S, Jones CA, et al. Discordant indigenous and provider frames explain challenges in improving access to arthritis care: a qualitative study using constructivist grounded theory. Int J Equity Health. 2014;13(1):46. https://doi.org/10.1186 /1475-9276-13-46

11. Canadian Best Practices Portal. Aboriginal Ways Tried and True. Welcome to the Aboriginal Ways Tried and True: good public health practices in Aboriginal communities [Internet]. Ottawa (ON): Public Health Agency of Canada; 2015. 
12. Truth and Reconciliation Commission of Canada. Truth and Reconciliation Commission of Canada: Calls to Action. Winnipeg (MB): Truth and Reconciliation Commission of Canada; 2015.

13. Alkema GE, Wilber KH, Shannon GR, Allen D. Reduced mortality: the unexpected impact of a telephone-based care management intervention for older adults in managed care. Health Serv Res. 2007;42(4):1632-50. https://doi .org/10.1111/j.1475-6773.2006.00668.x

14. Mitton C, O'Neil D, Simpson L, Hoppins Y, Harcus S. Nurse-Physician Collaborative Partnership: a rural model for the chronically ill. Can J Rural Med. 2007;12(4):208-16.

15. McBrien KA, Ivers N, Barnieh L, et al. Patient navigators for people with chronic disease: a systematic review. PLoS One. 2018;13(2):e0191980. https:// doi.org/10.1371/journal.pone.0191980

16. Askew DA, Togni SJ, Schulter PJ, et al. Investigating the feasibility, acceptability and appropriateness of outreach case management in an urban Aboriginal and Torres Strait Islander primary health care service: a mixed methods exploratory study. BMC Health Serv Res. 2016;16:178. https:// doi.org/10.1186/s12913-016-1428-0

17. Feldman $\mathrm{CH}$, Wohlfahrt $\mathrm{A}$, Campos $\mathrm{A}$, et al. Can patient navigators improve adherence to disease-modifying antirheumatic drugs? Quantitative findings from a six-month single-arm pilot intervention. Arthritis Care Res (Hoboken). 2018;70(9):1400-5. https:// doi.org/10.1002/acr.23302

18. Wohlfahrt A, Campos A, Iversen MD, et al. Use of rheumatology-specific patient navigators to understand and reduce barriers to medication adherence: Analysis of qualitative findings. PLoS One. 2018;13(7):e0200886. https://doi.org/10.1371/journal.pone .0200886

19. Lu MC, Guo HR, Livneh H, Lin MC, Lai NS, Tsai TY. The effectiveness of nurse-led case management for patients with rheumatoid arthritis in Taiwan. Int J Clin Pract. 2020;74(2):e13443. https://doi.org/10.1111/ijcp.13443
20. Nagaraj S, Kargard M, Hemmelgarn B, Fritzler M, White T, Barnabe C. Effectiveness of an outreach model of care for rheumatology specialty clinics to an on-reserve First Nations community. Int J Indig Health. 2018;13(1): 156-66. https://doi.org/10.32799/ijih .v13i1.30315

21. Barber CE, Thorne JC, Ahluwalia V, et al. Feasibility of measurement and adherence to system performance measures for rheumatoid arthritis in 5 models of care. J Rheumatol. 2018;45(11): 1501-8. https://doi.org/10.3899/jrheum .171284

22. Loyola-Sanchez A, Pelaez-Ballestas I, Crowshoe L, et al. "There are still a lot of things that I need": a qualitative study exploring opportunities to improve the health services of First Nations People with arthritis seen at an on-reserve outreach rheumatology clinic. BMC Health Serv Res. 2020; 20(1):1076. https://doi.org/10.1186 /s12913-020-05909-9

23. Chamberlain R, Rapp CA. A decade of case management: a methodological review of outcome research. Community Ment Health J. 1991;27(3):171-88. https://doi.org/10.1007/BF00752419

24. Brown AJ, Varcoe C, Smye V, ReimerKirkham S, Lynam MJ, Wong S. Cultural safety and the challenges of translating critically-oriented knowledge in practice. Nurs Philos An Int J Health Care Prof. 2009;10:167-79. https://doi.org/10.1111/j.1466-769X .2009.00406.x

25. First Nations Information Governance Centre. The First Nations Principles of $\mathrm{OCAP}^{\circledR}$ [Internet]. Akwesasne (ON): FNIGC; [cited 2020 Dec 1]. https:// fnigc.ca/ocap-training/

26. Haggerty JL, Roberge D, Freeman GK, Beaulieu C. Experienced continuity of care when patients see multiple clinicians: a qualitative metasummary. Ann Fam Med. 2013;11(3):262-71. https:// doi.org/10.1370/afm.1499

27. Kim K, Choi JS, Choi E, et al. Effects of community-based health worker interventions to improve chronic disease management and care among vulnerable populations: a systematic review. Am J Public Health. 2016; 106(4):e3-e28. https://doi.org/10.2105 /AJPH.2015.302987 